\title{
A COMPARATIVE STUDY OF SILODOSIN AND TAMSULOSIN IN TREATMENT OF LOWER URINARY TRACT SYMPTOMS ASSOCIATED WITH BENIGN PROSTATIC HYPERPLASIA
}

\author{
Nusrat Nabi', Shalini Gupta², Nasir Nabi Naikoo3, Mahesh Gupta4, Hajra Banoo5, Gulam Nabi Naikoo ${ }^{6}$ \\ ${ }_{1}^{1}$ Tutor, Department of Pharmacology, Rama Medical College Hospital \& Research Centre, Kanpur. \\ ${ }^{2}$ Assistant Professor, Department of Pharmacology, Rama Medical College Hospital \& Research Centre, Kanpur. \\ 3Tutor, Department of Pathology, Rama Medical College Hospital \& Research Centre, Kanpur. \\ 4 Professor, Department of Surgery, Rama Medical College Hospital \& Research Centre, Kanpur. \\ 5 Professor \& HOD, Department of Physiology, Rama Medical College Hospital \& Research Centre, Kanpur. \\ ${ }^{6}$ Emergency Physician (Retd.), Royal Commission Hospital, KSA.
}

\section{ABSTRACT}

\section{BACKGROUND}

Lower urinary tract symptoms (LUTS) associated with benign prostatic hyperplasia (BPH) are a common problem in elderly men. Selective alpha1-adrenergic antagonists are considered the first-line drugs in the medical management of BPH.

\section{OBJECTIVES}

Our study was planned as a single blind, randomised, controlled trial to compare the effectiveness and safety profile of the newer alpha1-adrenergic blocker, silodosin with the older established tamsulosin in men with LUTS associated with BPH.

\section{SETTING AND DESIGN}

A prospective randomised parallel group, single blind, active control study; carried out in a tertiary care teaching hospital.

\section{MATERIALS AND METHODS}

A total of 60 male BPH patients, aged above 50 years, were included in the study on the basis of International Prostate Symptom Score (IPSS). The subjects were randomised to receive either tamsulosin $0.4 \mathrm{mg}$ controlled release or silodosin $8 \mathrm{mg}$ once daily (pharmaco-equivalent doses) for a period of 12 weeks. The primary outcome of the study was the measure of reduction in IPSS. All the variables were assessed at regular intervals and all the emergent adverse events were also recorded.

\section{RESULTS}

The results of the study reflected that the IPSS and QOL at 12-weeks was significantly less than baseline in both the study groups. The groups remained comparable in terms of IPSS and QOL at all visits and had no statistical significance. There was no significant changes in prostate size, postvoid residual urine volume and peak urine flow rate as well. Both the treatments were well tolerated However, there was a significant impact on sexual function in silodosin arm as compared with tamsulosin. Retrograde ejaculation was encountered only in silodosin arm and postural hypotension only in tamsulosin arm.

\section{CONCLUSIONS}

Silodosin is as efficient as tamsulosin in the treatment of LUTS associated with BPH. However, its impact on sexual function and retrograde ejaculation may be bothersome for sexually active patients.

\section{KEYWORDS}

Alpha1-adrenergic Antagonists, International Prostate Symptom Score, Peak Urinary Flow Rate, Quality of Life Score, Randomised Controlled Trial.

HOW TO CITE THIS ARTICLE: Nabi N, Gupta S, Naikoo NN et al. A comparative study of silodosin and tamsulosin in treatment of lower urinary tract symptoms associated with benign prostatic hyperplasia. J. Evolution Med. Dent. Sci. 2016;5(77):5673-5677, DOI: $10.14260 /$ jemds/2016/1280

\section{INTRODUCTION}

Lower urinary tract symptoms (LUTS) associated with benign prostatic hyperplasia (BPH) are a common problem in men over 70 years of age.

Financial or Other, Competing Interest: None.

Submission 05-08-2016, Peer Review 12-09-2016,

Acceptance 19-09-2016, Published 23-09-2016.

Corresponding Author:

Dr. Nusrat Nabi,

Rama Medical College Hospital \& Research Centre,

Staff Accommodation,

Mandhana, Kanpur-209217,

Uttar Pradesh, India.

E-mail: nusratnabinaikoo@gmail.com

DOI: $10.14260 /$ jemds $/ 2016 / 1280$

(c) (i) $(-)$
In men, the symptoms of BPH usually start in 50 s and by the age of 70 years $80 \%$ of men suffer from BPH-related LUTS. ${ }^{1}$ $\mathrm{BPH}$ affects both glandular epithelium and stromal connective tissue of the prostate; as such LUTS results from a combination of fixed mechanical obstruction of the prostatic urethra and dynamic obstruction of the prostatic muscle activity. ${ }^{2}$

Although surgery is the definitive management of symptomatic BPH, but apart from being invasive, there are potential complications of surgery, the most dreaded being permanent urinary incontinence. ${ }^{3}$ Hence, pharmacological management remains the physician's first choice for patients of $\mathrm{BPH}$. There are two major classes of drugs used for the treatment of symptomatic BPH namely; the $\alpha_{1}$-adrenoreceptor blockers (e.g. tamsulosin, silodosin) and the $5 \alpha$-reductase enzyme inhibitors (e.g. finasteride, dutasteride). 
The $\alpha_{1}$-adrenoreceptor blockers result in smooth muscle relaxation causing the prostatic urethra to dilate; and are expected to provide relatively rapid symptom relief (2-6 weeks).

Currently the first-line drugs in the medical management of BPH are $\alpha_{1}$-adrenoreceptor blockers. ${ }^{4}$ Recent studies have revealed that $\alpha 1-A R$ can be subclassified into three subtypes: $\alpha 1 \mathrm{~A}, \alpha 1 \mathrm{~B}$, and $\alpha 1 \mathrm{D}$. Reports suggest that contraction of the human prostate is regulated mainly via the $\alpha 1 \mathrm{~A}-\mathrm{AR}$ subtype. On the other hand, $\alpha 1 \mathrm{~B}-\mathrm{ARs}$ are mainly located in the vascular smooth muscle; thereby, regulating the cardiac compensatory mechanisms and blood pressure, especially in the elderly. ${ }^{5}$ Thus, drugs selective for $\alpha 1 \mathrm{~A}-\mathrm{AR}$ have beneficial effects on the symptoms associated with BPH and less effect on blood pressure as compared to non-selective $\alpha 1$-AR antagonists. ${ }^{6}$ Silodosin, an $\alpha 1 \mathrm{~A}$-adrenoceptor blocker, developed by Kissei Pharmaceutical Co. Ltd. (Matsumoto, Japan), is said to be highly selective for this receptor subtype. ${ }^{7}$

In clinical practice, tamsulosin is widely being used throughout the world for the treatment of BPH. There have been only few comparative studies of the efficacy of silodosin and tamsulosin. Hence, the objective of our study was to compare the effectiveness and safety of silodosin in elderly Indian men with LUTS associated with BPH, in comparison to the older established $\alpha_{1}$-blocker tamsulosin. ${ }^{8}$

\section{MATERIALS AND METHODS}

This study was conducted as a single blind, randomised, controlled trial at the outpatient department of surgery and general medicine, at a tertiary care hospital in Kanpur. The study was conducted over a period of 8 months, from October 2015 to May 2016 and a total of 60 subjects were included in the study. Approval from the Institutional Ethics Committee was obtained to conduct the study. The inclusion criteria were as follows: newly visiting, ambulatory male patients, aged above 50 years complaining of troublesome LUTS, IPSS. ${ }^{9}>7$; QOL score $\geq 3$ points; prostate volume $\geq 20 \mathrm{~mL}$ and peak urinary flow rate $(\mathrm{Qmax})<16 \mathrm{~mL} / \mathrm{s}$. Patients with LUTS not associated with $\mathrm{BPH}$, acute retention of urine in past 6 months, raised prostate specific antigen (PSA) level, history of prostatic or per urethral surgery, chronic illness (hypertension, diabetes mellitus, CAD, thyroid dysfunction, etc.) use of medication during the 2-month period before the study or concomitant medication such as; anticholinergics, androgenic or oestrogenic influence, diuretics or other $\alpha$-adrenergic antagonists; were excluded from the study. A written informed consent was taken from all the subjects enrolled in the study.

Randomisation of the subjects was done in 1:1 ratio, into two study groups by random number allocation; receiving either tamsulosin $0.4 \mathrm{mg}$ controlled-release capsule or silodosin $8 \mathrm{mg}$ capsule once daily after dinner for 12 weeks. Standard marketed brands of both the drugs were used and administered in a single blind manner, with medication identity not being revealed to the patients. Allocation concealment was achieved using the serially numbered, opaque, sealed envelope technique. The patients received the total medication in three instalments at 0,4 and 8 weeks; and were followed up at 4,8 and 12 weeks from the start of the treatment.

The primary endpoint for the evaluation of efficacy was the change in total IPSS from baseline. The secondary endpoints to assess the efficacy as well as safety were (a) changes in objective parameters such as proportion of subjects achieving IPSS $<8$, change in prostate size and residual urine volume as assessed on ultrasonography; and change in peak urine flow rate as assessed on uroflowmetry (Qmax); both done by treatment allocation blinded operators (b) changes in subjective symptoms; as assessed by quality of life score (QOL). The subjective evaluation done by IPSS and QOL was carried out at the baseline, before administration of the drug and at 4, 8 and 12 weeks after the treatment. All the objective parameters were measured at the baseline and end of the study, by ultrasonography and uroflowmetry. The quality of life (QOL) assessment was done on a 7-point scale questionnaire that forms part of the broader symptom scoring.

Safety assessment was done by recording the vital signs of the subjects and all the treatment-emergent adverse events in the structured case report form, at each study visit. History of postural hypotension and retrograde ejaculation (in sexually active patients) was specifically taken at each visit.

\section{Statistical Analysis}

SPSS software 21 version was used for data analysis. One way ANOVA was used to compare the mean values among the given groups. Tukey's HSD test was used for multiple comparisons between different groups.

\section{RESULTS}

A total of 60 patients were enrolled in the study; with 30 patients each in silodosin and tamsulosin arm.

\begin{tabular}{|c|c|c|}
\hline $\begin{array}{c}\text { Parameters } \\
\text { (Mean+SD) }\end{array}$ & $\begin{array}{c}\text { Tamsulosin } \\
\text { Group (n=30) }\end{array}$ & $\begin{array}{c}\text { Silodosin } \\
\text { Group (n=30) }\end{array}$ \\
\hline Age (Years) & $63.60 \pm 7.80$ & $64.40 \pm 8.52$ \\
\hline Weight (Kg) & $69.00 \pm 7.56$ & $67.20 \pm 7.76$ \\
\hline $\begin{array}{c}\text { Symptom } \\
\text { Duration (Months) }\end{array}$ & $10.00 \pm 4.09$ & $10.90 \pm 4.42$ \\
\hline Table 1: Baseline Characteristics of the Subjects \\
in the Two Study Groups \\
\hline
\end{tabular}

The baseline profile of the subjects is summarised in Table 1. It was observed that the majority of patients were in their sixties and the mean symptom duration at presentation was 10 months in both groups. The general characteristics of both the groups were comparable and thus adequately matched.

\begin{tabular}{|c|c|c|c|}
\hline $\begin{array}{c}\text { IPSS } \\
\text { (Mean+SD) }\end{array}$ & $\begin{array}{c}\text { Tamsulosin } \\
\text { Group (n=30) }\end{array}$ & $\begin{array}{c}\text { Silodosin } \\
\text { Group (n=30) }\end{array}$ & $\begin{array}{c}\text { p- } \\
\text { value }\end{array}$ \\
\hline $\begin{array}{c}\text { Baseline } \\
\text { ( } \text { weeks) }\end{array}$ & $18.40 \pm 1.80$ & $18.00 \pm 2.03$ & $>0.05$ \\
\hline $\begin{array}{c}\text { 1st follow-up } \\
\text { (4 weeks) }\end{array}$ & $12.40 \pm 1.80$ & $11.20 \pm 1.90$ & $<0.05$ \\
\hline $\begin{array}{c}\text { 2nd follow-up } \\
\text { (8 weeks) }\end{array}$ & $9.10 \pm 2.00$ & $8.10 \pm 1.97$ & $<0.05$ \\
\hline $\begin{array}{c}\text { End of study } \\
\text { (12 weeks) }\end{array}$ & $6.20 \pm 2.20$ & $5.20 \pm 2.10$ & $>0.05$ \\
\hline $\begin{array}{c}\text { Within group } \\
\text { p-value }\end{array}$ & $<0.05$ & $<0.05$ & \\
\hline \multicolumn{4}{|c|}{ Table 2: Comparison of Change in IPSS } \\
of the Two Study Groups \\
\hline \multicolumn{4}{|c}{}
\end{tabular}

It is reflected in Table 2 that the serial change in IPSS in both the groups declined significantly from baseline. However, at the end of the study, the scores remained comparable between the two groups with no statistical significance. 


\begin{tabular}{|c|c|c|c|}
\hline $\begin{array}{l}\text { QOL score } \\
\text { (Mean+SD) }\end{array}$ & $\begin{array}{c}\text { Tamsulosin } \\
\text { Group } \\
(n=30)\end{array}$ & $\begin{array}{c}\text { Silodosin } \\
\text { Group } \\
(\mathrm{n}=\mathbf{3 0})\end{array}$ & $\begin{array}{c}\text { p- } \\
\text { value }\end{array}$ \\
\hline $\begin{array}{l}\text { Baseline } \\
(0 \text { weeks })\end{array}$ & $4.90 \pm 0.71$ & $4.88 \pm 0.72$ & $>1.00$ \\
\hline $\begin{array}{l}\text { 1st follow-up } \\
\text { (4 weeks) }\end{array}$ & $3.90 \pm 0.76$ & $3.80 \pm 0.74$ & $>0.20$ \\
\hline $\begin{array}{l}2^{\text {nd }} \text { follow-up } \\
\text { (8 weeks) }\end{array}$ & $3.10 \pm 0.76$ & $2.90 \pm 0.73$ & $>0.10$ \\
\hline $\begin{array}{l}\text { End of study } \\
\text { (12 weeks) }\end{array}$ & $2.50 \pm 0.68$ & $2.30 \pm 0.65$ & $>0.25$ \\
\hline $\begin{array}{l}\text { Within group p- } \\
\text { value }\end{array}$ & $<0.001$ & $<0.001$ & \\
\hline \multicolumn{4}{|c|}{$\begin{array}{c}\text { Table 3: Comparison of QOL Scores of } \\
\text { the Two Study Groups }\end{array}$} \\
\hline
\end{tabular}

Table 3 depicts the QOL score changes in both the study groups; which again declined significantly from baseline in both the groups $(\mathrm{p}<0.001)$ but remained comparable between the groups throughout the study period, with no statistical significance.

\begin{tabular}{|c|c|c|c|}
\hline $\begin{array}{l}\text { USG parameters } \\
\text { (Mean+SD) }\end{array}$ & $\begin{array}{c}\text { Tamsulosi } \\
\text { n Group } \\
(n=30)\end{array}$ & $\begin{array}{c}\text { Silodosin } \\
\text { Group } \\
(\mathbf{n}=\mathbf{3 0})\end{array}$ & $\begin{array}{c}\text { p- } \\
\text { value }\end{array}$ \\
\hline $\begin{array}{l}\text { Prostate volume } \\
\text { (mL) } \\
\text { Baseline ( } 0 \text { weeks) } \\
\text { End of study } \\
(12 \text { weeks) } \\
\text { Within group p- } \\
\text { value }\end{array}$ & $\begin{array}{c}38.70 \pm 1.49 \\
37.60 \pm 1.64 \\
>0.06\end{array}$ & $\begin{array}{c}40.00 \pm 1.20 \\
37.40 \pm 1.68 \\
>0.05\end{array}$ & $\begin{array}{l}>0.66 \\
>0.78\end{array}$ \\
\hline $\begin{array}{l}\text { Postvoid residual } \\
\text { volume (mL) } \\
\text { Baseline ( } 0 \text { weeks) } \\
\text { End of study } \\
\text { (12 weeks) } \\
\text { Within group p- } \\
\text { value }\end{array}$ & $\begin{array}{c}55.90 \pm 1.70 \\
55.40 \pm 1.40 \\
>0.18\end{array}$ & $\begin{array}{c}55.20 \pm 1.27 \\
49.60 \pm 2.60 \\
>0.28\end{array}$ & $\begin{array}{l}>0.05 \\
>0.07\end{array}$ \\
\hline
\end{tabular}

As reflected in Table 4, there was no significant change in prostate size or post-void residual urine after 12 weeks of treatment in both the groups.

\begin{tabular}{|c|c|c|c|}
\hline $\begin{array}{c}\text { Uroflowmetry } \\
\text { Parameter } \\
\text { (Mean+SD) }\end{array}$ & $\begin{array}{c}\text { Tamsulosin } \\
\text { Group } \\
(n=30)\end{array}$ & $\begin{array}{c}\text { Silodosin } \\
\text { Group } \\
(\mathrm{n}=30)\end{array}$ & $\begin{array}{c}\text { p- } \\
\text { value }\end{array}$ \\
\hline \multicolumn{4}{|l|}{$\begin{array}{l}\text { Peak urine flow } \\
\text { rate }(\mathrm{mL} / \mathrm{s})\end{array}$} \\
\hline Baseline ( 0 weeks) & $15.30 \pm 0.70$ & $15.10 \pm 0.70$ & $>0.05$ \\
\hline \multicolumn{4}{|l|}{ End of study } \\
\hline \multicolumn{4}{|l|}{ Within group p- } \\
\hline value & $>0.05$ & $>0.05$ & \\
\hline \multicolumn{4}{|c|}{ Table 5: Comparison of Peak Urine Flow Rate } \\
\hline
\end{tabular}

The values of pre- and post-treatment peak urine flow rate as summarised in Table 5 reflect modest improvements, which once again were not significant statistically.

\section{Safety Analysis}

Both the drugs were well tolerated. There were no significant changes in vital signs. 13 treatment emergent adverse events were encountered in the silodosin arm (commonest dyspepsia, 5 cases) and 12 in the tamsulosin arm (commonest headache, 3 cases). Among the 15 sexually active men, 4 events of retrograde ejaculation (23.08\%) were reported in the silodosin arm and none in the tamsulosin arm. There were no reports of postural hypotension in the silodosin arm; however, 3 events of postural hypotension were recorded in the tamsulosin arm. All adverse events were mild and transient, requiring no hospitalisations. Compliance was excellent in both study arms.

\section{DISCUSSION}

Lower urinary tract symptoms (LUTS) associated with benign prostatic hyperplasia (BPH) are a common problem in elderly men; characterised by the enlargement of the prostate caused by cellular hyperplasia of both glandular and stromal elements. ${ }^{2,10} \alpha$-blockers are currently the preferred first-line therapy for all men with moderate or severe LUTS/BPH; according to the European Association of Urology 2011 guidelines. ${ }^{11}$ This study was planned to mirror the actual conditions in clinical practice and assess the evaluating drug in the post-marketing phase. Hence, the objective of our study was to compare the effectiveness and safety of silodosin in elderly Indian men with LUTS associated with $\mathrm{BPH}$, in comparison to the older established $\alpha_{1}$-blocker tamsulosin. ${ }^{8}$

In the present study, the final IPSS scores at 12 weeks were significantly less than baseline for both tamsulosin as well as silodosin (Table 2), though the scores were comparable between the two study groups at the end of 12-weeks' duration of the study; with no statistical significance. The number of subjects who became completely or relatively symptom free (achieved IPSS $<8$ ) were also comparable between the two groups, which is 18 in both the groups. These results suggest that silodosin effectiveness is similar to tamsulosin in the short-term treatment of BPH in Indian men.

The results of our study are in accordance with other studies from different countries. In a multicentric RCT carried out by Chapple et al ${ }^{12}$, it was found that the change in IPSS total score from the baseline with both silodosin and tamsulosin was significantly superior to that with placebo: Difference between placebo and active drug was-2.3 (95\% confidence interval [CI], -3.2 to -1.4 ) with silodosin and -2.0 (95\% CI, -2.9 to -1.1 ) with tamsulosin. According to total IPSS, the responder rates were also significantly higher with silodosin (66.8\%) and tamsulosin (65.4\%) than with placebo (50.8\%) reflecting that the overall efficacy of silodosin is not inferior to tamsulosin.

Yu et al ${ }^{13}$ conducted a non-inferiority trial and found that of the 170 (81.3\%) patients who completed the study, 86.2\% in the silodosin group versus $81.9 \%$ in the tamsulosin group achieved $\mathrm{a} \geq 25 \%$ decrease in IPSS ( $\mathrm{P}=0.53)$. The mean difference (silodosin minus tamsulosin) in IPSS change from baseline was -0.60 ( $95 \% \mathrm{CI}-2.15$ to -0.95$)$; which confirmed the non-inferiority of silodosin $4 \mathrm{mg}$ twice daily to tamsulosin $0.2 \mathrm{mg}$ once daily.

In 2006, Kawabe $\mathrm{K}$ et $\mathrm{al}^{14}$ reported the first double-blind, placebo-controlled, RCT comparing tamsulosin and silodosin. Patients received silodosin $4 \mathrm{mg}$ twice daily, tamsulosin $0.2 \mathrm{mg}$ once daily, or a placebo for 12-weeks. 
The changes in the total IPSS from the baseline in the silodosin, tamsulosin, and placebo groups were-8.3,-6.8 and -5.3 respectively. It was concluded from the results of the study that the silodosin was better than a placebo and not inferior to tamsulosin.

From a pooled analysis of two RCTs in United States, Marks et al 15 reported that symptom relief was rapid and differences (silodosin versus placebo) in IPSS score and subscores increased by week 12 .

Ding et $\mathrm{al}^{16}$ in a recent systematic review have also suggested that silodosin is effective therapy for LUTS in men with $\mathrm{BPH}$ and is not inferior to $0.2 \mathrm{mg}$ tamsulosin.

The results of various earlier studies. ${ }^{17,18}$ reflect that selective $\alpha_{1}$-blockers are not expected to affect prostate size, which is in affirmation to the results of our study. Our study observed non-significant changes in prostate volume, postvoid residual volume (Table 4) and peak urine flow rate (Qmax) as secondary endpoints. The values of pre- and post-treatment peak urine flow rate as summarised in Table 5, reflect modest non-significant improvements in other uroflowmetry parameters.

An increase in Qmax was observed in all groups in a study by Chapple et al ${ }^{12}$ wherein the adjusted mean change from baseline to end was $3.77 \mathrm{~mL} / \mathrm{s}$ for silodosin, $3.53 \mathrm{~mL} / \mathrm{s}$ for tamsulosin and $2.93 \mathrm{~mL} / \mathrm{s}$ for placebo. The changes for silodosin and tamsulosin were not statistically significant versus placebo. At the endpoint, the percentage of responders by Qmax was $46.6 \%, 46.5 \%$, and $40.5 \%$ in the silodosin, tamsulosin and placebo treatment groups respectively, which once again was not statistically significant.

In the study by Yu et al, ${ }^{13}$ the changes in mean Qmax from baseline were comparable between tamsulosin and silodosin; with no statistical significance. There was also statistically non-significant reduction in prostate volume in either group.

In our study, the QOL declined significantly from baseline in both groups $(\mathrm{p}<0.001)$ but remained comparable between the groups throughout the study period, with no statistical significance (Table 3). However, silodosin significantly improved the QOL scores from the early stage of administration. Silodosin also significantly improved nocturia in addition to voiding symptoms, which among LUTS markedly affects QOL. Reports suggest that there are increasing numbers of BPH/LUTS patients who wish to be treated for voiding symptoms as well as for storage symptoms such as nocturia. ${ }^{19,20}$ These observations suggested that silodosin improved patient satisfaction by improving a wide range of symptoms.

In our study, both the treatments were well tolerated as assessed by clinical parameters. The most specific adverse reaction was retrograde ejaculation found in silodosin group and dizziness or postural hypotension found in tamsulosin group.

In addition to retrograde ejaculation due to inhibition of the contraction of the bladder neck; inhibition of the contraction of seminal vesicle and vas deferens is also reported to be involved in the mechanism of ejaculatory disorder; and the expression of $\alpha 1 \mathrm{~A}$ receptor has been confirmed in these tissues. ${ }^{21}$

Moreover, a clinical trial in the USA found that tamsulosin induces abnormal ejaculation in some American patients ( $8.4 \%$ at $0.4 \mathrm{mg}$ daily and $18.1 \%$ at $0.8 \mathrm{mg}$ daily).
Hence, abnormal ejaculation is not considered an adverse reaction specific to silodosin, and has been shown to be reversible with discontinuation of drug administration. ${ }^{22}$

According to a phase III double-blind study in the USA, ejaculatory disorders were observed in $28 \%$ of the patients after administration of silodosin at $8 \mathrm{mg}$ once-daily. 15

Yu et al.13 reported in their study that patients receiving silodosin had a significantly higher incidence of abnormal ejaculation ( $9.7 \%$ vs. tamsulosin $1.0 \%$; $\mathrm{P}=0.009)$.

During the development stage of silodosin in Japan and USA, high incidences of abnormal ejaculation were reported with silodosin (22-28\%).7,23 We encountered a similar incidence of $23 \%$ in the silodosin arm, but none in the tamsulosin arm. Although sexual activity normally diminishes with age but impaired sexual performance still remains an undesirable adverse effect of BPH management. The important fact being that the risk of ejaculation disorders due to $\alpha_{1}$ blocker therapy for BPH is much lower than that from surgical intervention for $\mathrm{BPH}$.

The main limitation of this study was that although the treatment period was adequate to assess the symptom relief but it was too short for observe any potential reduction of prostate size. As with all single blinded trials, the possibility of bias in subjective assessment by the attending investigator was present in this study as well. Also no arrangement to assess the persistence of adverse events beyond the study period was done.

From the observations of the present study, it can be concluded that silodosin is as effective as tamsulosin in the treatment of LUTS associated with BPH. Both the drugs offer symptom relief. Retrograde ejaculation was encountered only with silodosin and postural hypotension only with tamsulosin; making tamsulosin the drug of choice for comparatively younger sexually active men. However, larger and longer duration clinical studies are needed to confirm this comparability in the treatment of symptomatic BPH.

\section{ACKNOWLEDGMENTS}

We would like to thank Dr. Himika Mukhopadhyay, postgraduate trainee, Department of Pathology, for assistance in laboratory investigations; and Mrs. Chitra R Chauhan, statistician, Department of Community Medicine, for assistance in data analysis.

\section{REFERENCES}

1. Chute CG, Panser LA, Girman CJ, et al. The prevalence of prostatism: a population-based survey of urinary symptoms. J Urol 1993;150(1):85-9.

2. Roehrborn CG, McConnell JD. Etiology, pathophysiology, epidemiology and natural history of benign prostatic hyperplasia. $8^{\text {th }}$ ed. In: Walsh PC, Retik AB, Vaughan ED, et al, eds. Campbell's Urology. Philadelphia: W. B. Saunders Co 2002:1297-336.

3. Reznicek SB. Common urologic problems in the elderly. Prostate cancer, outlet obstruction, and incontinence require special management. Postgrad Med 2000;107(1):163-4, 167-70, 177-8.

4. Kaplan SA. Use of alpha-adrenergic inhibitors in treatment of benign prostatic hyperplasia and implications on sexual function. Urology 2004;63(3): 428-34. 
5. Hatano A, Takahashi H, Tamaki M, et al. Pharmacological evidence of distinct alpha 1-adrenoceptor subtypes mediating the contraction of human prostatic urethra and peripheral artery. Br J Pharmacol 1994;113(3):723-8.

6. Kaplan SA. Alpha-blocker therapy: current update. Rev Urol 2005;7(Suppl 8):S34-42.

7. Yoshida M, Homma Y, Kawabe K. Silodosin, a novel selective alpha 1A-adrenoceptor selective antagonist for the treatment of benign prostatic hyperplasia. Expert Opin Investig Drugs 2007;16(12):1955-65.

8. Wilt TJ, Donald MR, Rutks I. Tamsulosin for benign prostatic hyperplasia. Cochrane Database Syst Rev 2003;1:CD002081.

9. Barry MJ, Fowler FJ, O'Leary MP, et al. The American urological association symptom index for benign prostatic hyperplasia. The measurement committee of the American urological association. J Urol 1992; 148(5):1549-57.

10. Jacobsen SJ, Jacobson DJ, Girman CJ, et al. Treatment for benign prostatic hyperplasia among community dwelling men: the Olmsted county study of urinary symptoms and health status. J Urol 1999;162(4):1301-6.

11. Oelke M, Bachmann A, Descazeaud A, et al. Arnhem: European association of urology. Guidelines on the treatment of non-neurogenic male LUTS 2011:8-12.

12. Chapple CR, Montorsi F, Tammela TL, et al. Silodosin therapy for lower urinary tract symptoms in men with suspected benign prostatic hyperplasia: results of an international, randomized, double-blind, placebo- and active-controlled clinical trial performed in Europe. Eur Urol 2011;59(3):342-52.

13. Yu HJ, Lin AT, Yang SS, et al. Non-inferiority of silodosin to tamsulosin in treating patients with lower urinary tract symptoms (LUTS) associated with benign prostatic hyperplasia (BPH). BJU Int 2011;108(11):1843-8.

14. Kawabe K, Yoshida M, Homma Y. Silodosin, a new alpha1Aadrenoceptor-selective antagonist for treating benign prostatic hyperplasia: results of a phase III randomized, placebo-controlled, double-blind study in Japanese men. BJU Int 2006;98(5):1019-24.
15. Marks LS, Gittelman MC, Hill LA, et al. Rapid efficacy of the highly selective alpha1A-adrenoceptor antagonist silodosin in men with signs and symptoms of benign prostatic hyperplasia: pooled results of 2 phase 3 studies. J Urol 2009;181(6):2634-40.

16. Ding H, Du W, Hou ZZ, et al. Silodosin is effective for treatment of LUTS in men with BPH: a systematic review. Asian J Androl 2013;15(1):121-8.

17. Lepor H, Williford WO, Barry MJ, et al. The efficacy of terazosin, finasteride, or both in benign prostatic hyperplasia. Veterans affairs cooperative studies benign prostatic hyperplasia study group. N Engl J Med 1996;335(8):533-9.

18. McConnell JD, Roehrborn CG, Bautista OM, et al. The longterm effect of doxazosin, finasteride, and combination therapy on the clinical progression of benign prostatic hyperplasia. N Engl J Med 2003;349(25):2387-98.

19. Homma Y, Yamaguchi O, Hayashi K, et al. Epidemiologic survey of lower urinary tract symptoms in Japan. Urology 2006;68(3):560-4

20. Yoshimura K, Arai Y, Ichioka K, et al. Symptom-specific quality of life in patients with benign prostatic hyperplasia. Int J Urol 2002;9(9):485-90.

21. Kobayashi K, Masumori N, Hisasue $\mathrm{S}$, et al. Inhibition of seminal emission is the main cause of an ejaculation induced by a new highly selective alpha1A-blocker in normal volunteers. J Sex Med 2008;5(9):2185-90.

22. Höfner K, Claes H, De Reijke TM, et al. Tamsulosin 0.4 mg once daily: effect on sexual function in patients with lower urinary tract symptoms suggestive of benign prostatic obstruction. Eur Urol 1999;36(4):335-41.

23. Silodosin. Available from: http://www.drugbank.ca/drugs/DB06207. 